\title{
Polymorphisms in the DAD1 and OXA1L genes are associated with asthma and atopy in a South American population
}

\author{
Anaque de Oliveira Pires ${ }^{\mathrm{a}}$, Gerson de Almeida Queiroz ${ }^{\mathrm{a}}$, Milca de Jesus Silva ${ }^{\mathrm{a}}$, \\ Raimon Rios da Silva ${ }^{a}$, Hugo Bernardino Ferreira da Silva ${ }^{a}$, Norma Vilany Queiroz Carneiro ${ }^{a}$, \\ Héllen Freitas Fonseca ${ }^{a}$, Maria Borges Rabelo de Santana ${ }^{a}$, Regina Santos Nascimento ${ }^{a}$, \\ Neuza Maria Alcântara-Neves ${ }^{\mathrm{b}}$, Gustavo Nunes de Oliveira Costa ${ }^{\mathrm{a}}$, Ryan dos Santos Costa ${ }^{\mathrm{a}}$, \\ Maurício L. Barreto ${ }^{c}$, Camila Alexandrina Figueiredo ${ }^{a, *}$
}

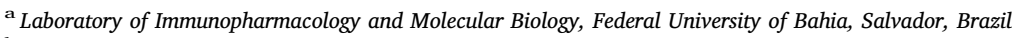

${ }^{\mathrm{b}}$ Laboratory of Allergy and Acarology, Federal University of Bahia, Salvador, Brazil

' Gonçalo Moniz Research Center, Oswaldo Cruz Foundation, Salvador, Brazil

\section{A R T I C L E I N F O}

\section{Keywords:}

Asthma

Allergy

Polymorphisms

$D A D 1$

OXA1L

\begin{abstract}
A B S T R A C T
Atopic asthma, which is characterized by the chronic inflammation and morbidity of airways, is a disease of great complexity, and multiple genetic and environmental factors are involved in its etiology. In the first genome-wide association study (GWAS) conducted in Brazil for asthma, a positive association was found between atopic asthma and a variant (rs1999071), which is located between the DAD1 and OXA1L genes, although neither gene has previously been reported to be associated with asthma or allergies. The DAD1 gene is involved in the regulation of programmed cell death, and $O X A 1 L$ is involved in biogenesis and mitochondrial oxidative phosphorylation. This study aimed to evaluate how polymorphisms in DAD1 and OXA1L are associated with asthma and markers of atopy in individuals from the Salvador cohort of the SCAALA (Social Change Asthma and Allergy in Latin America) program. The DNA of 1220 individuals was genotyped using the Illumina 2.5 Human Omni Bead chip. Logistic regression analyses were performed with PLINK 1.9 software to verify the association between $D A D 1$ and OXA1L polymorphisms and asthma and atopic markers, adjusted for sex, age, helminth infections and ancestry markers, using an additive model. The DAD1 and OXA1L genes were associated with some of the evaluated phenotypes, such as asthma, skin prick test (SPT), specific IgE for aeroallergens, and Th1/ Th2-type cytokine production. Using GPCR, as well as in silico gene expression analysis, we have demonstrated that some of the polymorphisms in both genes are able to affect their respective gene expression levels. In addition, $D A D 1$ was over-expressed in asthmatic patients when compared with controls. Thus, our findings demonstrate that variants in both the DAD1 and OXA1L genes may affect atopy and asthma in a Latin American population with a high prevalence of asthma.
\end{abstract}

\section{Introduction}

Atopic conditions, such as atopic dermatitis, rhinitis and asthma, are some of the most common non-communicable diseases and are caused by chronic inflammatory reactions of type I hypersensitivity. They have a strong impact on quality of life and represent a substantial and growing socioeconomic burden for societies (Wight et al., 2017).

Asthma affects approximately 334 million people worldwide, and although it affects individuals across all age groups, it is one of the top 20 chronic conditions in the worldwide disability ranking among children 5-14 years of age (Asher and Pearce, 2014).

Asthma morbidity is characterized by variable and recurrent symptoms, including chronic inflammation, reversible obstruction of the airways and increased bronchial hyperresponsiveness. It is a complex disease with multiple genetic and environmental risk factors and a marked phenotypic heterogeneity (Yang et al., 2010).

In recent decades, large studies on asthma and atopy in diverse populations throughout the world have identified genetic polymorphisms that either serve as risk factors or offer protection for such conditions, especially in children (Strachan and Pearce, 2011). Although

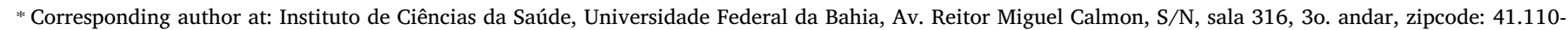
100, Salvador, Bahia, Brazil.

E-mail address: camilavf@ufba.br (C.A. Figueiredo). 
there exist genome-wide association (GWA) and candidate gene studies for asthma and atopy, the first GWA study for asthma in Brazil was only recently published, in 2015. In that study, the single-nucleotide polymorphism (SNP) rs1999071, located in an intergenic region between the $D A D 1$ and $O X A 1 L$ genes in the $14 \mathrm{q} 11$ region, was described as a genetic risk factor for asthma (Costa et al., 2015).

The $D A D 1$ gene is known to be involved in the process of apoptosis, proving to be essential for the homeostasis and cell proliferation of various tissues (Nakashima et al., 1993). Apoptosis is known to be an essential process for normal development in multicellular organisms and to control inflammation, as well as immune homeostasis (Fuchs and Steller, 2015). A previous study has indicated that the increased expression of the DAD1 gene in the thymus and the peripheral immune system is associated with an increase in the proliferation of peripheral $\mathrm{T}$ lymphocytes in mice (Hong et al., 1999).

OXA1L is a gene encoding the Oxa1 protein, which is involved in the biogenesis of mitochondrial oxidative phosphorylation machinery (Herrmann and Neupert, 2003; Hildenbeutel et al., 2008). Mitochondrial dysfunction may be involved in the physiopathology of many diseases, such as Kearns Sayre Syndrome, Leigh-syndrome or Leber's Hereditary Optic Neuropathy (Dankowski et al., 2016). It has been previously shown that mitochondrial dysfunction is commonly caused by polymorphisms in mitochondrial DNA and inadequate repair mechanisms (Wallace and Chalkia, 2013). In addition, (Mabalirajan and Ghosh, 2013) stated that there is a relationship between the immunopathology of asthma and mitochondrial biology, involving oxidative stress, calcium ion homeostasis and apoptosis pathways. It has been previously shown by (Jaffer et al., 2015) that mitochondria are relevant for remodeling in asthma, and dysfunctional mitochondria are evident in the smooth muscle cells of airways and in the lung epithelium of asthmatic patients (Leishangthem et al., 2013; Li and Shang, 2014).

Thus, in the present study, we have investigated the association between DAD1 and OXA1L gene variants and asthma and allergic markers in an attempt to understand the mechanisms through which these variants affect asthma in Latin America to better characterize the disease and to suggest alternative pathways for the treatment of this illness.

\section{Methods}

\subsection{Study population}

The study was performed in children living in the city of Salvador, Northeast, Brazil, which has a population of approximately 2.8 million inhabitants. The study population consisted of approximately 1220 children, between 4 and 11 years of age, and has been described in previous studies of the group (Barreto et al., 2006; Figueiredo et al., 2009; Queiroz et al., 2017; Rodrigues et al., 2008). The children were recruited to the Salvador cohort of the SCAALA (Social Change Asthma and Allergy in Latin America) Program (Barreto et al., 2007).

To collect data, questionnaires based on the ISAAC (International Study of Asthma and Allergies in Childhood) phase 2 study (Asher et al., 1995) were used, with questions regarding asthma symptoms translated in to Portuguese (Alcantara-Neves et al., 2012), and the survey was conducted by properly trained field workers during home visits. Written consent was acquired from the parents or guardians of the children, and interviews were conducted in their presence. The project was approved by the ethics committees of the Federal University of Bahia (registry 003-05/CEP-ISC) and the National Council of Ethics in Research (CONEP, resolution number 15 895/2011).

\subsection{Definition of asthma symptoms}

Children were classified as asthmatic when parents or guardians reported wheezing associated with any of the following: the diagnosis of asthma by a physician at any time, wheezing with exercise during the previous 12 months, four or more episodes of wheezing during the previous 12 months, or night waking due to wheezing episodes during the previous 12 months. These classification parameters are more specific than the classification parameters most commonly reported by studies using the ISAAC questionnaire, which only consider reported wheezing during the previous 12 months. Children who did not meet these criteria were classified as non-asthmatic.

\subsection{Specific IgE to aeroallergens}

To determine the specific IgE levels, tests were performed using the ImmunoCAP assay (ThermoFisher, Waltham, Massachusetts, USA) for the following allergens: Dermatophagoides pteronyssinus, Blomia tropicalis, Periplaneta americana and Blatella germanica. Children who had specific IgE levels greater than or equal to $0.7 \mathrm{kU} / \mathrm{L}$ and/or a positive SPT for at least one test allergen were defined as atopic.

\subsection{Blood collection and skin prick tests (SPT)}

The children were evaluated by a medical team in a mobile clinic, where blood was collected, and skin prick testing was performed for the above mentioned aeroallergens, as well as for dog and cat epithelia and a fungal mix. Saline solution was used as the negative control, and a histamine solution at $10 \mathrm{mg} / \mathrm{ml}$ was used as the positive control. After $15 \mathrm{~min}$, the reactions were read, and a diameter size of $3 \mathrm{~mm}$ greater than the negative control was considered positive.

Heparinized blood was collected, the plasma was prepared to measure specific IgE levels for the aeroallergens and whole blood cultures were analyzed to measure the production of cytokines in the cell supernatants.

\subsection{Cell culture and measurement of IL-5, IL-10, IL-13 and IFN- $\gamma$ by ELISA}

Cells were cultured at a 1:4 dilution in RPMI medium (Gibco, Auckland, New Zealand) containing $10 \mathrm{mM}$ of glutamine (SigmaAldrich, Inc., St. Louis, Missouri, USA) and $100 \mu \mathrm{g} / \mathrm{ml}$ gentamycin (Sigma-Aldrich, Inc. St. Louis, Missouri, USA) within $6 \mathrm{~h}$ following collection in heparinized tubes. For the detection of IL-5, IL-10, IL-13 and IFN- $\gamma$, cell cultures were maintained in a humidified atmosphere of $5 \% \mathrm{CO} 2$ at $37^{\circ} \mathrm{C}$ for 5 days, either without stimulation, to evaluate spontaneous production, or with stimulation using $2,5 \mu \mathrm{g} / \mathrm{ml}$ of $B$. tropicalis extract (Greer, Brazil). The concentrations of each cytokine were measured by sandwich ELISA, using commercial kits, following the manufacturer's recommendations (BD PharMingen, San Diego, CA, USA). There was no significant association between IL-5 and IL-10 cytokines (data not shown). The respective low and high detection limits (in $\mathrm{pg} / \mathrm{ml}$ ) were 15.6 and 500 for IFN- $\gamma$ and 62.5 and 4000 for IL-13. Children were considered responsive when the measured values for both cytokines fell within the detection ranges.

\subsection{Genotyping}

The DNA was extracted from peripheral blood samples using a Flexigene ${ }^{@}$ DNA Kit (Qiagen, Hilden, Germany), and we performed genotyping using a commercial panel, a Illumina Bead Chip HumanOmni 2.5 Kit (www.illumina.com), through the Consortium EPIGEN-Brazil (https://epigen.grude.ufmg.br). The genetic information for $D A D 1$ was extracted from positions $23,033,807$ to $23,058,143$ (location: NC_000014.9) on chromosome 14. The genetic information for OXA1L was extracted from positions $23,235,731$ to $23,240,998$ (location: NC_000014.9) on chromosome 14. The following filters were applied for quality control: a genotyping call rate of less than 0.98 ; an imbalance of the Hardy-Weinberg equilibrium with a $P$-value of less than $10^{-4}$; and a $P$-value for the minor allele frequency (MAF) of less than 1\% (Laurie et al., 2010). A total of 33 markers were identified in 
$D A D 1$, but only 26 of these were analyzed following the application of the quality control parameters. Similarly, a total of 10 markers were identified in OXA1L, but only 5 of these were analyzed following the application of the quality control parameters.

\subsection{RNA extraction and cDNA production}

To evaluate the expression levels of the DAD 1 and $O X A 1 L$ genes, RNA was isolated from the whole blood cell culture using the RNeasy Mini Kit (Qiagen, Hamburg, Germany), according to the manufacturer's protocol. Subsequently, $0.3 \mu \mathrm{g}$ of total RNA from each sample was reverse transcribed into cDNA using $200 \mathrm{U}$ of Superscript III Reverse Transcriptase (Life Technologies, Carlsbad, CA, USA) and $500 \mathrm{ng}$ of Oligo (dT) (Life Technologies, Carlsbad, CA, USA), according to the manufacturer's instructions. Sterilized and filtered DEPC-treated water was used in all cDNA reactions. This step was performed as previously described by (Rios et al., 2017).

\subsection{Real time quantitative polymerase Chain reaction ( $q R T-P C R$ )}

Presynthesized Taqman ${ }^{\circledR}$ Gene Expression Assays (Applied Biosystems, Foster City, CA, USA) were used to amplify the following sequences (Applied Biosystems primers/probes set numbers are shown in parentheses): DAD1 (Hs00154671_m1), OXA1L (Hs00192329_m1) and $\beta$-actin (Hs99999903_m1). cDNA samples derived from the investigated genes were detected by a QuantStudio $12 \mathrm{~K}$ Sequence Detection System (Applied Biosystems, Foster City, CA, USA), according to the manufacturer's recommendations. Each qRT-PCR assay was performed with $10 \mathrm{ng}$ of the cDNA sample in $10 \mu \mathrm{L}$ of Taqman-PCR Mastermix 2X (Applied Biosystems, Foster City, CA, USA) and $1 \mu \mathrm{L}$ of the respective primer/probe set and was purified using deionized $\mathrm{H} 2 \mathrm{O}$ q.s. $20 \mu \mathrm{L}$. The gene expression levels were normalized to $\beta$-actin levels. Relative quantification was performed by the comparative threshold cycle $(\Delta \Delta \mathrm{CT})$ method, as previously described (Hellemans et al., 2007; Orlando et al., 1998; Vandesompele et al., 2002).

\subsection{Genetic risk score for asthma}

Genetic risk score analysis was performed to determine the degree of risk in the presence of more than one allele of any SNP, such as rs1681577 (DAD1) and rs4981436 (OXA1L), which were both associated with asthma in the present study. A score number was assigned according to the presence of risk alleles. For this analysis, the web tool SNPstats (www.snpstats.net) was used (Sole et al., 2006).

\subsection{In silico functional analysis}

In silico gene expression analyses were performed for the phenotypeassociated SNPs using the GTEx portal (www.gtexportal.org) in the following tissues: lung, fibroblasts and whole blood, according to the genotype of each SNP.

RegulomeDB (www.regulomedb.org) is a database that annotates SNPs with known and predicted regulatory elements in the intergenic regions of the $H$. sapiens genome. Known and predicted regulatory DNA elements include regions of DNAase hypersensitivity, transcription factor binding sites, and promoter regions that have been biochemically characterized as regulators of transcription. This database uses a score ranging from 1 to 7 . Lower scores indicate increasing evidence that a variant may be located in a functional region, indicating that a certain polymorphism may generate possible effects on TFs (Factors Binding to Transcription), which may affect the regulation of nearby gene expression. Scores from 1a to $1 \mathrm{f}$ indicate that the SNP is likely to affect binding and is linked to the expression of a gene target; scores from $2 \mathrm{a}$ to $2 \mathrm{c}$ indicate that the SNP is likely to affect binding; the scores $3 \mathrm{a}$ and $3 \mathrm{~b}$ indicate that the SNP is less likely to affect binding; scores of 4,5 , or 6 indicate that there is minimal binding evidence that the SNP affects binding; and a score of 7 indicates that no data regarding the SNP function are available.

The rSNPBase (http://rsnp.psych.ac.cn) is a database that provides annotations focused on regulatory SNPs that are involved in a wide range of regulation types, including proximal, distal and post-transcriptional regulation, and that helps to identify their potentially regulated genes. Micro RNA regulation describes SNPs within mature miRNA, and RNA binding protein-mediated regulation is involved in RNA binding protein-mediated post-transcriptional regulation (Guo et al., 2014).

\subsection{Statistical analysis}

The analyses for associations between polymorphisms in the DAD1 and OXA1L genes and asthma or atopy were performed using a nonadjusted bivariate logistic regression model and a multivariate model, adjusted for sex, age, helminth infections and individual ancestry, which was estimated as previously described (Fernanda Lima-Costa et al., 2015).

The additive genetic model was used in all analyses.Adaptive permutations were also employed in the bivariate and multivariate analyses, as previously described by (Teixeira et al., 2017). The adaptive permutations were calculated to provide a computationally intensive approach to generating significance levels. Multiple comparison problems have been managed using methods that control the false discovery rate, such as a permutation test (Lage-Castellanos et al., 2010). This test preserves the correlational structure between SNPs (Purcell et al., 2007). The LD analysis was performed using Haploview software, and all genetic data were analyzed using PLINK 1.9 software. We considered significant associations to be those with $P$-values $\leq 0.05$. Statistical analysis of DAD1 and OXA1L gene expression levels was performed using GraphPad 6 software, usinga $t$-test for parametric data and a Mann-Whitney test for non-parametric data.

\section{Results}

\subsection{Characteristics of the study population}

Table 1 presents the descriptive characterization of the study population, which was composed of 946 non-asthmatic and 274 asthmatics participants. Moreover, $53.5 \%$ of the children were male, and the majority of them were between 6 and 7 years old (35.6\%). Of the 1220 original children, analyses were limited to those for which genotype and phenotype data were available. Statistically significant differences $(P<0.001)$ were observed between asthmatic and non-asthmatic subjects for the evaluated atopic and immunological characteristics, a cross all demographics.

\subsection{Description of the DAD1 and OXA1L polymorphisms}

Table 2 shows the descriptions of the analyzed SNPs from our population that were associated with the considered phenotypes. A total of 21 polymorphisms were analyzed, the majority of which are intron variants, with sixteen occurring in the DAD1 gene and five occurring in the OXA1L gene. All SNPs had a Minor Allele Frequency (MAF) of at least $1 \%$ and up to $42 \%$ and remained within the parameters for the Hardy-Weinberg equilibrium (HWE) that were set for quality control.

\subsection{Regulatory characteristics of polymorphisms}

We described whether the SNPs identified in either gene had known regulatory mechanisms, summarized as "yes" or "no" in Table 3. The polymorphisms rs1051101, rs4981436, rs17619 and rs8572 are involved in proximal regulation. The SNPs rs1681577, rs1051101, rs3811189, rs4981436, rs17619 and rs8572 may influence distal regulation. The polymorphisms rs1681577, rs1051101 and rs3811189 
Table 1

Demographic characteristics and atopic and immunological markers in the studied population, separated by asthmatic or non-asthmatic status.

\begin{tabular}{|c|c|c|c|c|c|}
\hline \multirow[t]{2}{*}{ Variables } & \multicolumn{5}{|c|}{ Subject group (1220) } \\
\hline & $\begin{array}{l}\text { Non- } \\
\text { Asthmatics } \\
(946)\end{array}$ & $\%$ & $\begin{array}{l}\text { Asthmatics } \\
\text { (274) }\end{array}$ & $\%$ & $P$-value \\
\hline \multicolumn{6}{|l|}{ Age } \\
\hline$\leq 5$ years & 314 & 33,2 & 132 & 48,2 & $<0.001$ \\
\hline $6-7$ years & 337 & 35,6 & 88 & 32,1 & \\
\hline$\geq 8$ years & 291 & 30,8 & 54 & 19,7 & \\
\hline \multicolumn{6}{|l|}{ Sex } \\
\hline Male & 506 & 53,5 & 151 & 55,1 & $<0.001$ \\
\hline Female & 436 & 46,1 & 123 & 44,9 & \\
\hline \multicolumn{6}{|l|}{ Specific IgE for } \\
\hline D. pteronyssinus & 179 & 18,9 & 91 & 33,2 & $<0.001$ \\
\hline \multicolumn{6}{|c|}{ Skin prick test for } \\
\hline D. pteronyssinus & 131 & 13,8 & 62 & 22,6 & $<0.001$ \\
\hline P. americana & 120 & 12,7 & 49 & 17,9 & $<0.001$ \\
\hline Dog epithelium & 7 & 0,7 & 6 & 2,2 & $<0.001$ \\
\hline \multicolumn{6}{|c|}{$\begin{array}{l}\text { Spontaneous cytokine } \\
\text { production by } \\
\text { peripheral blood } \\
\text { cells }^{\mathrm{a}}\end{array}$} \\
\hline IL-13 & 313 & 33,1 & 83 & 30,3 & $<0.001$ \\
\hline \multicolumn{6}{|c|}{$\begin{array}{c}\text { Cytokines production } \\
\text { upon } B \text {. tropicalis } \\
\text { stimulation }^{\mathrm{b}}\end{array}$} \\
\hline IFN- $\gamma$ & 145 & 15,3 & 53 & 19,3 & $<0.001$ \\
\hline
\end{tabular}

Data were analyzed using the chi-square test.

a Response of asthmatic and non-asthmatic children from the lowest detection point for each cytokine in an unstimulated cell culture.

b Response of asthmatic and non-asthmatic children from the lowest detection point for each cytokine in a cell culture following stimulation with $B$. tropicalis.

may influence post-transcriptional regulation. In addition, the same table shows the values obtained using the RegulomeDB platform that correspond to the regulatory and functional characteristics of these SNPs. The score of " $1 \mathrm{f}$ " for rs1051101 indicates that it may affect binding and is linked to the expression of a gene target; the score of " $2 \mathrm{~b}$ " for rs1681577 indicates that it may affect binding; the score of " $3 a$ " for rs3811189 indicates that it is less likely to affect binding; and the scores "4" and " 5 " for the polymorphisms rs4981436, rs17619 and rs8572 indicate that there is minimal binding evidence. These scores were obtained as described in the methods section.

\subsection{Association of SNPs in DAD1 and OXA1L with asthma and atopy}

Table 4 shows the significant associations between DAD1 polymorphisms and asthma and markers of allergy. The $P$-values refer to the applied permutational test. The polymorphism rs1681577 (OR: 0.75; CI: 0.57-0.99) was negatively associated with asthma. The SNPs rs3811189 (OR: 1.31; CI: 1.07-1.61) and rs1051101 (OR: 1.25; CI: $1.02-1.54$ ), found in $D A D 1$, were positively associated with spontaneous IL-13 production. No association was found between the SNPs in $D A D 1$ and allergy markers of (data no shown).

Table 5 shows the significant associations between OXA1L gene polymorphisms, asthma and markers of allergy. The SNP rs4981436 (OR: 1.42; CI: 1.08-1.85), an intronic polymorphism, was positively associated with asthma. Another SNP, the missense polymorphism rs8572, was positively associated with several allergic markers, such as the skin prick tests for dog epithelium (OR: 2.23; CI: 1.02-4.85), $P$. americana (OR: 1.33; CI: 1.04-1.71), and D. pteronyssinus (OR: 1.33; CI: 1.05-1.69), and the production of specific IgE for D. pteronyssinus (OR: 1.26; CI: 1.03-1.56). Another missense SNP, rs17619 (OR: 0.69; CI: 0.51-0.93), was negatively associated with $B$. tropicalis-stimulated IFN$\gamma$ production.
Table 2

Characterization of the SNPs evaluated with in DAD1 and OXA1L.

\begin{tabular}{|c|c|c|c|c|c|c|}
\hline CHR & SNP & $\mathrm{A} 1$ & A2 & MAF & HWE & Function \\
\hline \multicolumn{7}{|c|}{$D A D 1$ gene } \\
\hline 14 & rs10137999 & $\mathrm{C}$ & $\mathrm{T}$ & 0.18 & 0.84 & Intron variant \\
\hline 14 & rs10145997 & A & G & 0.34 & 0.70 & Intron variant \\
\hline 14 & rs1051101 & $\mathrm{T}$ & $\mathrm{C}$ & 0.25 & 0.76 & Utr variant 5 prime \\
\hline 14 & rs1681577 & G & $\mathrm{T}$ & 0.32 & 0.95 & Intron variant \\
\hline 14 & rs17119961 & A & G & 0.05 & 0.57 & Intron variant \\
\hline 14 & rs3811189 & $\mathrm{C}$ & $\mathrm{T}$ & 0.26 & 0.94 & Intron variant \\
\hline 14 & rs5742731 & A & G & 0.05 & 1 & Utr variant 5 prime \\
\hline 14 & rs5742744 & $\mathrm{C}$ & A & 0.07 & 0.02 & Intron variant \\
\hline 14 & rs5742745 & $\mathrm{C}$ & $\mathrm{A}$ & 0.15 & 0.45 & Intron variant \\
\hline 14 & rs5742759 & $\mathrm{C}$ & $\mathrm{T}$ & 0.02 & 1 & Intron variant \\
\hline 14 & rs5742803 & G & A & 0.18 & 0.78 & Intron variant \\
\hline 14 & rs5742812 & C & $\mathrm{T}$ & 0.11 & 0.14 & Intron variant \\
\hline 14 & rs5742814 & $\mathrm{C}$ & A & 0.19 & 0.51 & Intron variant \\
\hline 14 & rs5742835 & A & G & 0.38 & 0.34 & Intron variant \\
\hline 14 & rs5742847 & $\mathrm{T}$ & G & 0.18 & 0.92 & Intron variant \\
\hline 14 & rs5742857 & A & G & 0.10 & 0.16 & Intron variant \\
\hline 14 & rs1803479 & C & $\mathrm{T}$ & 0.16 & 0.75 & Utr variant 3 prime \\
\hline 14 & rs5742870 & G & $\mathrm{T}$ & 0.09 & 0.05 & Intron variant \\
\hline 14 & rs75551720 & G & A & 0.01 & 1 & Intron variant \\
\hline 14 & rs5742855 & $\mathrm{C}$ & $\mathrm{T}$ & 0.02 & 1 & Intron variant \\
\hline 14 & rs17119926 & $\mathrm{C}$ & $\mathrm{T}$ & 0.16 & 0.67 & Intron variant \\
\hline 14 & rs1051154 & $\mathrm{T}$ & $\mathrm{C}$ & 0.16 & 0.60 & Synonymous codon \\
\hline 14 & rs5742794 & $\mathrm{C}$ & $\mathrm{T}$ & 0.16 & 0.60 & Intron variant \\
\hline 14 & rs115874095 & $\mathrm{T}$ & $\mathrm{C}$ & 0.08 & 0.11 & Intron variant \\
\hline 14 & rs5742747 & G & $\mathrm{A}$ & 0.29 & 0.68 & Intron variant \\
\hline 14 & rs5742741 & A & G & 0.09 & 0.86 & Intron variant \\
\hline 14 & rs1051189 & $\mathrm{T}$ & $\mathrm{C}$ & 0.10 & 0.08 & Utr variant 3 prime \\
\hline 14 & rs117059425 & $\mathrm{C}$ & A & 0.01 & 1 & Intron variant \\
\hline 14 & rs5742831 & G & $\mathrm{T}$ & 0.01 & 1 & Intron variant \\
\hline 14 & rs5742858 & $\mathrm{T}$ & $\mathrm{C}$ & 0.09 & 0.11 & Intron variant \\
\hline 14 & rs8022143 & $\mathrm{C}$ & $\mathrm{T}$ & 0.01 & 1 & Intron variant \\
\hline 14 & rs202152368 & G & - & 0 & - & Intron variant \\
\hline 14 & kgp5702341 & $\mathrm{C}$ & - & 0 & - & - \\
\hline \multicolumn{7}{|c|}{ OXA1L gene } \\
\hline 14 & rs200470407 & $\mathrm{C}$ & $\mathrm{T}$ & 0.22 & 0.69 & Synonymous codon \\
\hline 14 & rs17619 & A & G & 0.21 & 0.61 & Missense, upstream variant $2 \mathrm{~KB}$ \\
\hline 14 & rs3764164 & G & A & 0.42 & 0.95 & $\begin{array}{l}\text { Intron variant, upstream variant } 2 \\
\mathrm{~KB}\end{array}$ \\
\hline 14 & rs4981436 & $\mathrm{C}$ & $\mathrm{T}$ & 0.13 & 0.28 & Intron variant \\
\hline 14 & rs8572 & G & A & 0.28 & 0.36 & Missense, upstream variant $2 \mathrm{~KB}$ \\
\hline 14 & rs115891437 & G & A & 0.01 & 1 & Missense, upstream variant $2 \mathrm{~KB}$ \\
\hline 14 & rs1957374 & A & G & 0.26 & 0.05 & $\begin{array}{l}\text { Synonymous codon, upstream } \\
\text { variant } 2 \mathrm{~KB}\end{array}$ \\
\hline 14 & rs2075846 & $\mathrm{G}$ & A & 0.27 & 0.11 & Intron variant \\
\hline 14 & rs73586409 & $\mathrm{C}$ & $\mathrm{T}$ & 0.01 & 0.10 & Missense, upstream variant $2 \mathrm{~KB}$ \\
\hline 14 & rs199959164 & - & G & 0 & - & Intron variant \\
\hline
\end{tabular}

CHR, chromosome; SNP, single-nucleotide polymorphism; A1, polymorphic allele; A2, wild allele; MAF, minor allele frequency; HWE, Hardy-Weinberg equilibrium.

Table 3

Data regarding SNP function from in silico analyses, using rSNPBase and RegulomeDB on the identified SNPs in DAD1 and OXA1L.

\begin{tabular}{|c|c|c|c|c|c|}
\hline $\mathrm{SNP}^{\mathrm{a}}$ & $\begin{array}{l}\text { Proximal } \\
\text { regulation }\end{array}$ & $\begin{array}{l}\text { Distal } \\
\text { regulation }\end{array}$ & $\begin{array}{l}\text { miRNA } \\
\text { regulation }\end{array}$ & $\begin{array}{l}\text { RNA- } \\
\text { binding- } \\
\text { protein- } \\
\text { mediated } \\
\text { regulation }\end{array}$ & $\begin{array}{l}\text { RegulomeDB } \\
\text { score }^{\text {b }}\end{array}$ \\
\hline \multicolumn{6}{|l|}{ DAD1 Gene } \\
\hline rs1681577 & No & Yes & No & Yes & $2 b$ \\
\hline rs1051101 & Yes & Yes & No & Yes & $1 \mathrm{f}$ \\
\hline rs3811189 & No & Yes & No & Yes & $3 a$ \\
\hline \multicolumn{6}{|c|}{ OXA1L Gene } \\
\hline rs4981436 & Yes & No & No & No & 5 \\
\hline rs17619 & Yes & Yes & No & No & 4 \\
\hline rs8572 & Yes & Yes & No & No & 4 \\
\hline
\end{tabular}

\footnotetext{
a Single-nucleotide polymorphism.
}

b RegulomeDB score annotation. 
Table 4

Significant associations between DAD1 SNPs, asthma and spontaneous IL-13 production, using a logistic regression adjusted for sex, age, helminth infections, and ancestry markers.

\begin{tabular}{|c|c|c|c|c|c|c|}
\hline Gene & CHR & SNP & $\mathrm{A} 1$ & OR & CI $95 \%$ & P-value \\
\hline \multicolumn{7}{|c|}{ Asthma } \\
\hline$D A D 1$ & 14 & rs1681577 & G & 0.75 & $0.57-0.99$ & 0.033 \\
\hline \multicolumn{7}{|c|}{ Spontaneous IL-13production } \\
\hline$D A D 1$ & 14 & rs3811189 & $\mathrm{C}$ & 1.31 & $1.07-1.61$ & 0.008 \\
\hline$D A D 1$ & 14 & rs1051101 & $\mathrm{T}$ & 1.25 & $1.02-1.54$ & 0.031 \\
\hline
\end{tabular}

CHR, chromosome; SNP, single-nucleotide polymorphism; A1, polymorphic allele; OR, odds ratio; $\mathrm{CI}$, confidence interval.

* $P$-value considering adaptive permutations using the additive model.

Table 5

Significant associations between OXA1L SNPs and asthma and atopy markers, using a logistic regression adjusted for sex, age, helminth infections, and ancestry markers.

\begin{tabular}{|c|c|c|c|c|c|c|}
\hline Gene & CHR & SNP & A1 & OR & CI $95 \%$ & P-value \\
\hline \multicolumn{7}{|l|}{ Asthma } \\
\hline OXA1L & 14 & rs4981436 & $\mathrm{C}$ & 1.42 & $1.08-1.85$ & 0.010 \\
\hline \multicolumn{7}{|c|}{ Positive skin prick test for dog epithelium } \\
\hline OXA1L & 14 & rs8572 & $\mathrm{G}$ & 2.23 & $1.02-4.85$ & 0.030 \\
\hline \multicolumn{7}{|c|}{ Positive skin prick test for $P$. americana } \\
\hline OXA1L & 14 & rs8572 & G & 1.33 & $1.04-1.71$ & 0.028 \\
\hline \multicolumn{7}{|c|}{ Positive skin prick test for $D$. pteronyssinus } \\
\hline OXA1L & 14 & rs8572 & G & 1.33 & $1.05-1.69$ & 0.031 \\
\hline \multicolumn{7}{|c|}{ Production of specific IgE for $D$. pteronyssinus } \\
\hline OXA1L & 14 & rs8572 & G & 1.26 & $1.03-1.56$ & 0.023 \\
\hline \multicolumn{7}{|c|}{ Production of IFN- $\gamma$ stimulated with $B$. tropicalis } \\
\hline OXA1L & 14 & rs17619 & A & 0.69 & $0.51-0.93$ & 0.015 \\
\hline
\end{tabular}

CHR, chromosome; SNP, single-nucleotide polymorphism; A1, polymorphic allele; OR, odds ratio; CI, confidence interval.

* $P$-value considering adaptive permutations using the additive model.

\subsection{A cluster of variants increases asthma risk}

All combinations of rs1681577 (DAD1) and rs4981436 (OXA1L) genotypes were analyzed. We verified that the risk of asthma susceptibility was increased when the alleles that acted as risk factors were presented together, as shown in Table 6 and Fig. 1.

In the presence of two risk alleles, the susceptibility to asthma increased (OR: 1.92; 95\% CI: 1.02-3.59; $P$-value: 0.032), and in the presence of three risk alleles, the susceptibility to asthma was doubled (OR: 2.96; 95\% CI: 1.43-6.10; $P$-value: 0.0021 ), when compared with the susceptibility to asthma in the presence of any single risk allele.

\subsection{In silico expression of the DAD1 and OXA1L gene by GTEx portal}

The in silico expression levels of the DAD1 gene, in lung tissue and in transformed fibroblast cells obtained from individuals that carry the SNP rs1681577, are shown in Fig. 2. The levels of DAD1 expression are reduced in individuals that carry the rs 1681577 polymorphic $G$ allele (GTEx $P$-value: 0.0015 ; GTEx $P$-value: 0.00017 ) in the above mentioned

Table 6

Genetic risk scores for rs1681577 (DAD1) and rs4981436 (OXA1L) for susceptibility to asthma.

\begin{tabular}{lllll}
\hline Risk allele & Controls & Cases & OR $(95 \% \mathrm{CI})^{\mathrm{a}}$ & $P$-value \\
\hline 0 & $77(19.7 \%)$ & $13(13.8 \%)$ & 1.00 & - \\
1 & $313(80.3 \%)$ & $81(86.2 \%)$ & $1.59(0.83-3.02)$ & 0.15 \\
2 & $410(84.2 \%)$ & $124(90.5 \%)$ & $1.92(1.02-3.59)$ & 0.032 \\
3 & $85(52.5 \%)$ & $39(75 \%)$ & $2.96(1.43-6.10)$ & 0.0021 \\
\hline
\end{tabular}

${ }^{\text {a }}$ Adjusted by gender, age, helminth infections and ancestry markers.

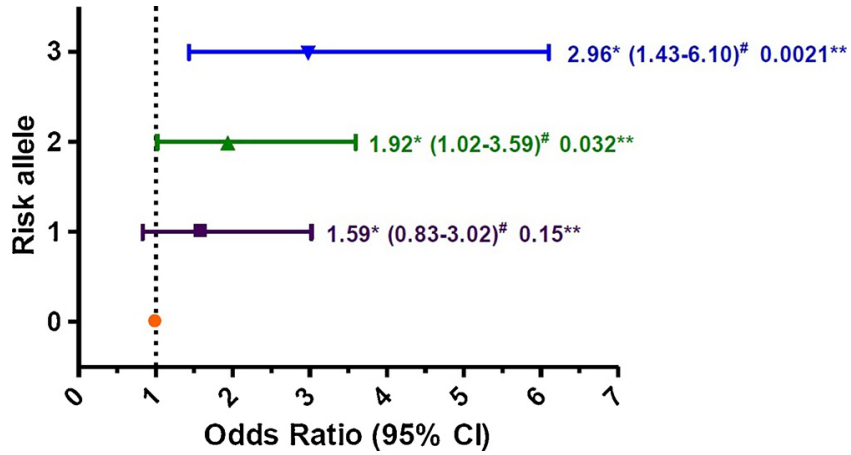

Fig. 1. Genetic risk score of rs1681577 (DAD1) + rs4981436 (OXA1L) association with asthma. The risk was higher according to the number of risk alleles. Adjusted by gender, age, helminth infection and ancestry markers. "Odds Ratio; ${ }^{*}$ (95\% Confidence Interval); ${ }^{* *} P$-value.

tissues.

Fig. 3 shows the in silico expression levels of the OXA1L gene in the whole blood tissue of individuals that carry the rs8572 SNP. Individuals that carry the rs8572 $\mathrm{G}$ allele had increased expression levels of the OXA1L gene (GTEx P-value: 0.030). No statistically significant association was found in the other evaluated tissues.

\subsection{Expression of DAD1 and OXA1L by real-time $q P C R$}

Fig. 4 shows the expression levels of the DAD1 and OXA1L genes as assessed by Real-Time qPCR. DAD1 expression levels were increased in asthmatic subjects when compared with control subjects ( $P$ value $=0.036)(A)$. However, although a trend was observed for increased OXA1L expression levels in asthmatic subjects when compared with control subjects, the result was not statistically significant $(P$ value $=0.931)(B)$.

\subsection{Linkage disequilibrium}

Fig. 5 shows the linkage disequilibrium (LD) analysis between the studied SNPs in the DAD1 and OXA1L genes. There is a high degree of linkage disequilibrium between the SNPs rs3811189 and rs1051101 that were found in the $D A D 1$ gene. However, no linkage disequilibrium was observed for the SNPs found in the OXA1L gene. The LD plots were generated by the Haploview 4.2 program using the PLINK 1.9 data set.

\section{Discussion}

Our study has demonstrated, for the first time, that genetic variants in the DAD1 and OXA1L genes are associated with asthma and markers of atopy. Previous studies have shown that DAD1 is present in the genome of humans, mice, chickens and other species and that this gene is expressed at varying levels in all tissues (Hong et al., 1997; Wang et al., 1997). In addition, the DAD1 gene is known to have anti-apoptotic activity, and previous experiments have shown that DAD1 is required for cell viability in several tissues (Nakashima et al., 1993; Silberstein et al., 1995).

The presence of the DAD1 SNP rs1681577 (G allele) was a protective factor for asthma, which can be explained, at least in part, by a decrease in $D A D 1$ expression levels in individuals carrying this SNP, as shown in Fig. 2A/B. Interestingly, rs1681577 is involved with some regulatory mechanisms (Table 3 ) that may play important roles in the transcriptional regulation of this gene.

The rs1051101 (T allele) and rs3811189 (C allele) SNPs in DAD1 were risk factors for IL-13 production. In addition, the SNPs rs1051101 (T allele) and rs3811189 appear to have an influence on the regulation of DAD1 expression, as they are also associated with transcription factors (Table 3 ). These polymorphisms are both positively associated 
(A)

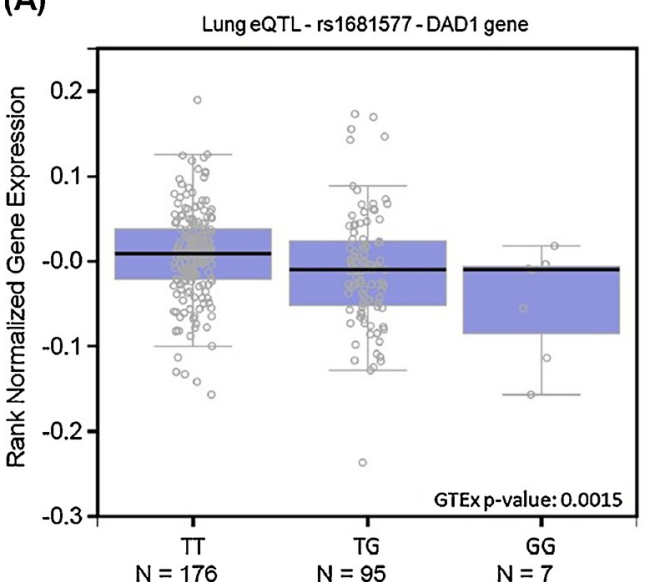

(B)

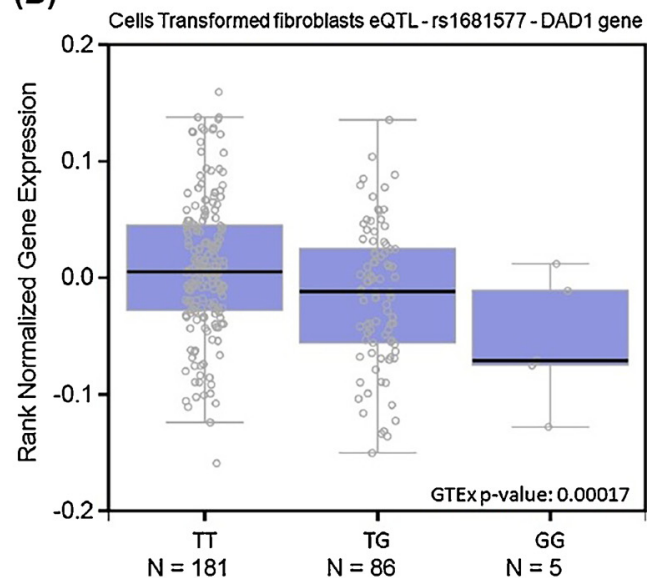

Fig. 2. SNP rs1681577 alters the in silico expression of DAD1 in lung tissue (A) and human cells transformed fibroblasts (B).

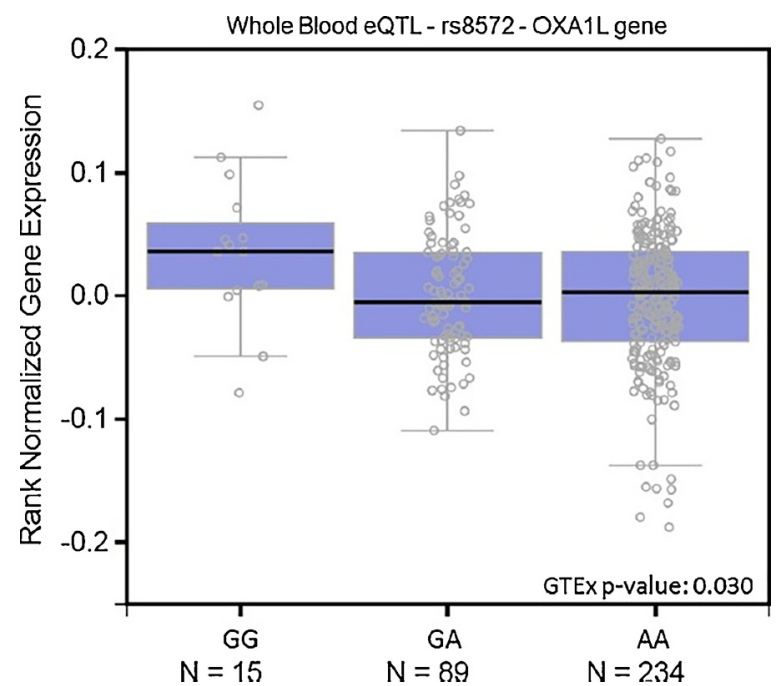

Fig. 3. SNP rs8572 (A) alters the in silico expression of $O X A 1 L$ in human whole blood cells.

with the same phenotype and also have high linkage disequilibrium values (Fig. 5).

In our gene expression assay, using RT-qPCR, the DAD1 gene had increased expression levels in asthmatic subjects when compared with control subjects (Fig. 4A). A previous study has shown that increased $D A D 1$ expression levels are associated with poor prognosis in Hodgkin's lymphoma and in hepatocellular, prostate and lung carcinomas (Kulke

(A)

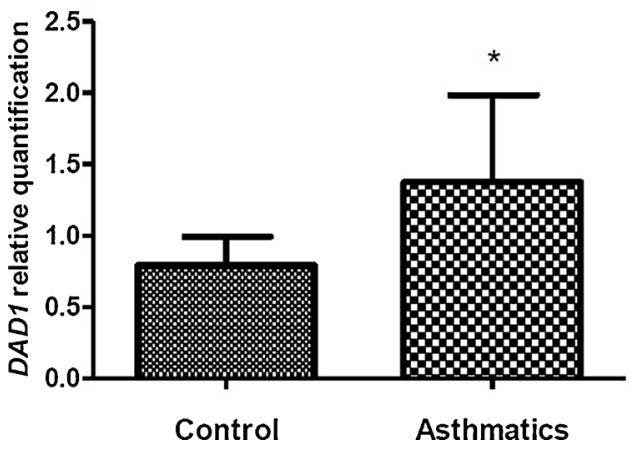

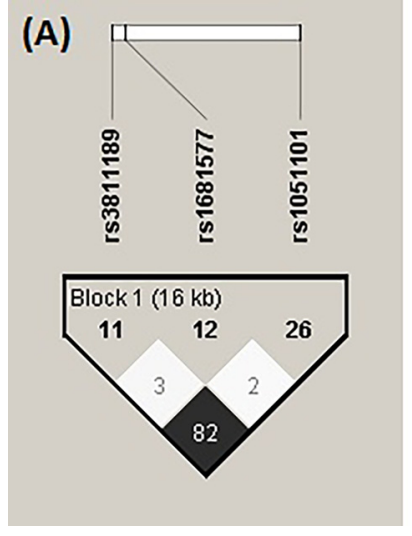

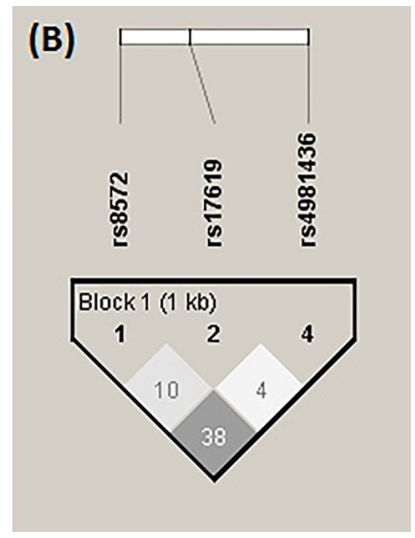

Fig. 5. LD plots of SNPs of the DAD1 and OXA1L genes, analyzed in asthmatic patients and control in Brazilian derived cohorts. The top horizontal bar illustrates the location of SNPs on a physical scale. The color of the squares illustrates the strength of pairwise $r^{2}$ values on a scale where black indicates perfect LD $\left(r^{2}=1\right)$, shades of gray indicates imperfect LD $\left(0<r^{2}<1\right)$ and white indicates perfect equilibrium $\left(r^{2}=0\right)$. The $r^{2}$ LD value is also indicated within each square. (A) LD in 3 SNPs of DAD1, (B) LD in 3 SNPs of OXA1L, both genes on chromosome 14.

et al., 2008). (Tanaka et al., 2001) have demonstrated that high DAD1 expression levels in hepatocellular carcinoma cells blocked apoptosis, increasing the survival of tumor cells.

A study in an American population identified the DAD1 SNP rs8005354 (allele C), which has no known function, as a risk factor for

(B)

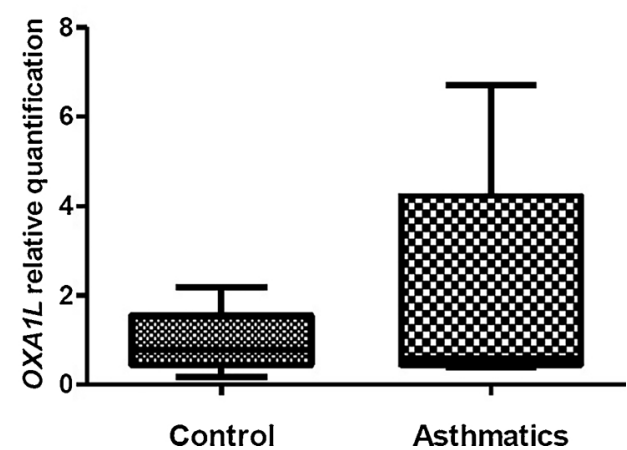

Fig. 4. Levels of $D A D 1$ gene expression $(P$-value $=0.036)(\mathrm{A})$ and $O X A 1 L(P$-value $=0.931)(\mathrm{B})$. The values were considered significant when $P$-value was $\leq 0.05$. 
neuroendocrine tumors (NET). This same group also suggested that the genetic variation in apoptosis-related genes may be associated with the risk of NET. This SNP is located in a region of high linkage disequilibrium. Thus, it is possible that rs8005354 is in disequilibrium with a functional variant in this region that is associated with increased DAD1 function or expression (Ter-Minassian et al., 2011).

(Wight et al., 2017) showed that increased cell proliferation is associated with the inflammatory process, which may explain why DAD1 expression may be increased in patients with asthma. A study using transgenic mice that over-express the $D A D 1$ gene in the thymus and in the peripheral immune system showed that there is a proliferation of peripheral T lymphocytes in these animals, as well as a substantially increased response to mitogens (Hong et al., 1999). In contrast, another study using DAD1-knockout mice showed that these animals die in uterus, presenting apoptotic characteristics (Nishii et al., 1999).

These findings allow us to hypothesize that $D A D 1$ may also be involved in the pathogenesis of asthma and atopy, as some of its polymorphisms are associated with other inflammatory conditions. We hypothesized that changes in $D A D 1$ expression levels may influence the regulation of apoptotic activity and the proliferation of inflammatory cells in atopic and asthmatic patients, as shown in Fig. 6.

In addition to DAD1, we also studied SNPs found in OXA1L. Some of the polymorphisms in the OXA1L gene were associated with the phenotypes evaluated in our study. The missense SNPs rs8572 (G allele) and rs17619 (A allele), were found to be, respectively, a risk factor for the development of some allergic conditions and a protective factor for IFN- $\gamma$ production in whole blood cultures stimulated with $B$. tropicalis. Because missense mutations are found in protein coding regions, they can alter the structure, stability and function of proteins, ultimately leading to several serious human diseases (Awan et al., 2017). These polymorphisms may still be involved in mechanisms of gene regulation (Table 3), performing important functions in OXA1L transcription.

In our study, the $\mathrm{G}$ allele of rs8572 was positively associated with atopy, which can be explained, at least in part, by increased expression levels of OXA1L in the presence of this polymorphic allele, as demonstrated in Fig. 2. In this study, the positive association between polymorphism rs4981436 and asthma suggests that it may be a risk factor for the development of asthma in our population. No statistically significant differences in OXA1L gene expression levels were found between asthmatic patients and control subjects; however, a trend toward higher OXA1L expression levels was observed in asthmatic individuals when compared with the controls (Fig. 3B).

Interestingly, genetic score analyses demonstrated that the combination of the variants rs1681577 (DAD1) and rs4981436 (OXA1L), which are both risk alleles, increased the risk for asthma when compared to the presence of any of these variants alone. Thus, this evidence demonstrates the relevant role that these polymorphisms may play in the development of this disease.

No previous study has associated polymorphisms in the OXA1L gene with any disease, including asthma or atopy. (Fernanda Lima-Costa et al., 2015) showed for the first time that the SNP rs1999071, which is a polymorphism present in the intergenic region between DAD1 and OXA1L genes, flanking the OXA1L gene, was strongly associated as a risk factor for asthma symptoms in Brazilian children. In addition, using in silico gene expression, the $\mathrm{C}$ allele of this variant was linked to increased expression levels of OXA1L inlung tissue.

(Wallace and Chalkia, 2013) showed that mitochondrial dysfunction is commonly caused by single-nucleotide polymorphisms (SNPs) of the mitochondrial genome and inadequate repair mechanisms. In addition, monogenic mutations of mitochondrial genes are known to cause severe mitochondrial dysfunction, leading to rare and multisystemic diseases, such as Kearns Sayre syndrome, Leigh syndrome or Leber's hereditary optic neuropathy (Moraes et al., 1989; Riordan-Eva and Harding, 1995; Suzuki et al., 2011; Wang et al., 2008).

Although asthma is not considered a mitochondrial syndrome, there is considerable overlap between the pathophysiology of asthma and

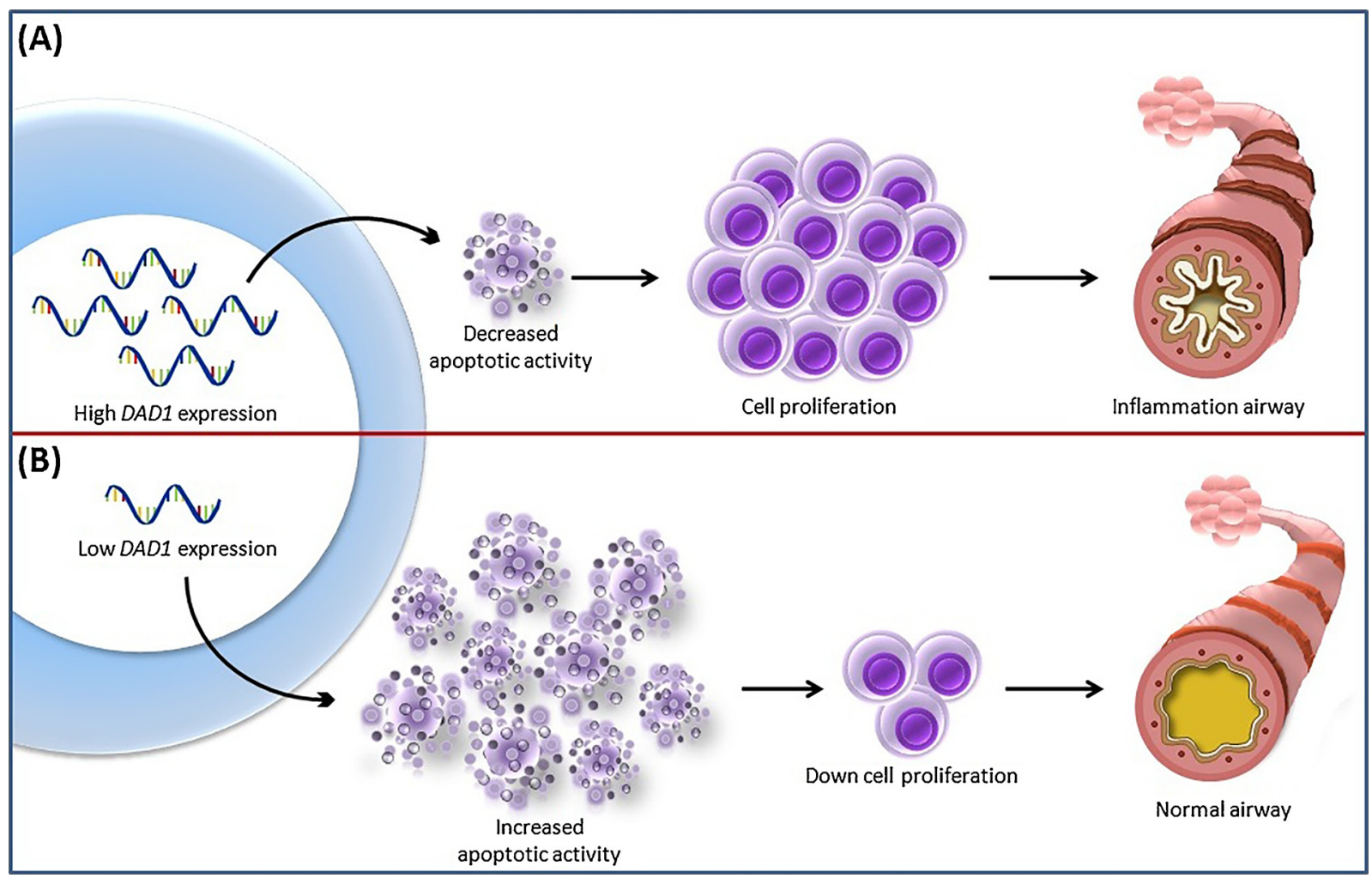

Fig. 6. Increased $D A D 1$ gene expression induces a decrease in apoptotic activity leading to increased cell proliferation and consequently an exacerbation of the inflammatory response (A). In other words, low expression of DAD1 increases apoptotic activity that will decrease cell proliferation and reduce the inflammatory response (B). 
mitochondrial biology, in terms of oxidative stress, the homeostasis of calcium ions and apoptosis (Mabalirajan and Ghosh, 2013). (Jaffer et al., 2015) showed that mitochondrion is a key organelle of the signaling pathways relevant for remodeling in asthma, and airway remodeling occurs in all asthmatics, independent of severity (Redington and Howarth, 1997). As in other pathologies leading to lung remodeling, dysfunctional mitochondria are evident in the smooth muscle cells of the airway and in the lung epithelium of asthmatic patients, and in vivo models suggest perturbed mitochondrial function and biogenesis (Leishangthem et al., 2013; Li and Shang, 2014).

Due to the existing literature related to apoptosis and mitochondrial biogenesis and the influence of these mechanism on the pathophysiology of allergy and asthma, we hypothesized that the association of the polymorphisms in DAD1 and OXA1L may contribute to the immunopathology of asthma and allergy in our population.

\section{Conclusion}

To the best of our knowledge, this is the first study that demonstrates an association between genetic variants in DAD1 and OXA1L and asthma and atopic markers. The polymorphisms found in this study present a frequency of $1-42 \%$ in Brazil (Salvador, Bahia). We have demonstrated increased DAD1 expression levels in asthmatic individuals, and this finding indicates the possible involvement of this gene in the immunopathology of this morbidity. Further investigation is necessary to elucidate the functional mechanisms of these genes and to better understand the effect they may have on the increased incidence of atopy and asthma.

\section{Disclosures}

The authors have declared that no competing interests exist.

\section{Funding}

This study was funded by Conselho Nacional de Desenvolvimento Científico e Tecnológico (CNPq), Coordenação de Aperfeiçoamento de Pessoal de Nível Superior (CAPES) and Fundação de Amparo a Pesquisa do Estado da Bahia (FAPESB).

\section{Ethics}

The study was approved by the Ethics Committee of the Public Health Institute (register 003-05/CEP-ISC) of the Federal University of Bahia, Brazil.

\section{Acknowledgements}

This study is part of SCAALA (Social Change, Asthma and Allergy in Latin America) Program.

\section{References}

Alcantara-Neves, N.M., Veiga, R.V., Dattoli, V.C.C., Fiaccone, R.L., Esquivel, R., Cruz Á.A., Cooper, P.J., Rodrigues, L.C., Barreto, M.L., 2012. The effect of single and multiple infections on atopy and wheezing in children. J. Allergy Clin. Immunol. 129. https://doi.org/10.1016/j.jaci.2011.09.015.

Asher, I., Pearce, N., 2014. Global burden of asthma among children. Int. J. Tuberc. Lung Dis. 18, 1269-1278. https://doi.org/10.5588/ijtld.14.0170.

Asher, M.I., Keil, U., Anderson, H.R., Beasley, R., Crane, J., Martinez, F., Mitchell, E.A., Pearce, N., Sibbald, B., Stewart, A.W., 1995. International study of Asthma and Allergies in Childhood (ISAAC): rationale and methods. Eur. Respir. J. 8, 483-491. https://doi.org/10.1183/09031936.95.08030483.

Awan, F.M., Obaid, A., Ikram, A., Janjua, H.A., 2017. Mutation-structure-function relationship based integrated strategy reveals the potential impact of deleterious missense mutations in autophagy related proteins on hepatocellular carcinoma (HCC): a comprehensive informatics approach. Int. J. Mol. Sci. 18. https://doi.org/10.3390/ ijms18010139.

Barreto, M.L., Cunha, S.S., Alcântara-Neves, N., Carvalho, L.P., Cruz, Á.A., Stein, R.T.,
Genser, B., Cooper, P.J., Rodrigues, L.C., 2006. Risk factors and immunological pathways for asthma and other allergic diseases in children: background and methodology of a longitudinal study in a large urban center in Northeastern Brazil (Salvador-SCAALA study). BMC Pulm. Med. 6. https://doi.org/10.1186/1471-24666-15.

Barreto, M.L., Genser, B., Strina, A., Teixeira, M.G., Assis, A.M.O., Rego, R.F., Teles, C.A., Prado, M.S., Matos, S.M., Santos, D.N., dos Santos, L.A., Cairncross, S., 2007. Effect of city-wide sanitation programme on reduction in rate of childhood diarrhoea in northeast Brazil: assessment by two cohort studies. Lancet 370, 1622-1628. https:// doi.org/10.1016/S0140-6736(07)61638-9.

Costa, G.N.O., Dudbridge, F., Fiaccone, R.L., da Silva, T.M., Conceição, J.S., Strina, A., Figueiredo, C.A., Magalhães, W.C.S., Rodrigues, M.R., Gouveia, M.H., Kehdy, F.S.G., Horimoto, A.R.V.R., Horta, B., Burchard, E.G., Pino-Yanes, M., Del Rio Navarro, B., Romieu, I., Hancock, D.B., London, S., Lima-Costa, M.F., Pereira, A.C., Tarazona, E., Rodrigues, L.C., Barreto, M.L., 2015. A genome-wide association study of asthma symptoms in Latin American children. BMC Genet. 16, 141. https://doi.org/10.1186/ s12863-015-0296-7.

Dankowski, T., Schröder, T., Möller, S., Yu, X., Ellinghaus, D., Bär, F., Fellermann, K., Lehnert, H., Schreiber, S., Franke, A., Sina, C., Ibrahim, S.M., König, I.R., 2016. Malespecific association between MT-ND4 11719 A/G polymorphism and ulcerative colitis: a mitochondria-wide genetic association study. BMC Gastroenterol. 16. https:// doi.org/10.1186/s12876-016-0509-1.

Fernanda Lima-Costa, M., Rodrigues, L.C., Barreto, M.L., Gouveia, M., Horta, B.L., Mambrini, J., Kehdy, F.S.G., Pereira, A., Rodrigues-Soares, F., Victora, C.G., Tarazona-Santos, E., 2015. Genomic ancestry and ethnoracial self-classification based on 5,871 community-dwelling Brazilians (the epigen initiative). Sci. Rep. 5. https:// doi.org/10.1038/srep09812.

Figueiredo, C.A., Alcântara-Neves, N.M., Veiga, R., Amorim, L.D., Dattoli, V., Mendonça, L.R., Junqueira, S., Genser, B., Santos, M., de Carvalho, L.C.P., Cooper, P.J., Rodrigues, L., Barreto, M.L., 2009. Spontaneous cytokine production in children according to biological characteristics and environmental exposures. Environ. Health Perspect. 117, 845-849. https://doi.org/10.1289/ehp.0800366.

Fuchs, Y., Steller, H., 2015. Live to die another way: modes of programmed cell death and the signals emanating from dying cells. Nat. Rev. Mol. Cell Biol. https://doi.org/10. 1038/nrm3999.

Guo, L., Du, Y., Chang, S., Zhang, K., Wang, J., 2014. RSNPBase: a database for curated regulatory SNPs. Nucleic Acids Res. 42. https://doi.org/10.1093/nar/gkt1167.

Hellemans, J., Mortier, G., De Paepe, A., Speleman, F., Vandesompele, J., 2007. qBase relative quantification framework and software for management and automated analysis of real-time quantitative PCR data. Genome Biol. 8, R19. https://doi.org/10. 1186/gb-2007-8-2-r19.

Herrmann, J.M., Neupert, W., 2003. Protein insertion into the inner membrane of mitochondria. IUBMB Life. https://doi.org/10.1080/1521654031000123349.

Hildenbeutel, M., Habib, S.J., Herrmann, J.M., Rapaport, D., 2008. New insights into the mechanism of precursor protein insertion into the mitochondrial membranes. Int. Rev. Cell Mol. Biol. 268, 147-190. https://doi.org/10.1016/S1937-6448(08) 00805-8.

Hong, N.A., Cado, D., Mitchell, J., Ortiz, B.D., Hsieh, S.N., Winoto, A., 1997. A targeted mutation at the T-cell receptor alpha/delta locus impairs T-cell development and reveals the presence of the nearby antiapoptosis gene Dad1. Mol. Cell. Biol. 17, 2151-2157.

Hong, N.A., Kabra, N.H., Hsieh, S.N., Cado, D., Winoto, A., 1999. In vivo overexpression of Dad1, the defender against apoptotic death-1, enhances $\mathrm{T}$ cell proliferation but does not protect against apoptosis. J. Immunol. 163, 1888-1893 https://doi.org/ ji_v163n4p1888[pii].

Jaffer, O.A., Carter, A.B., Sanders, P.N., Dibbern, M.E., Winters, C.J., Murthy, S., Ryan, A.J., Rokita, A.G., Prasad, A.M., Zabner, J., Kline, J.N., Grumbach, I.M., Anderson, M.E., 2015. Mitochondrial-targeted antioxidant therapy decreases transforming growth factor- $\beta$-mediated collagen production in a murine asthma model. Am. J. Respir. Cell Mol. Biol. 52, 106-115. https://doi.org/10.1165/rcmb.2013-05190C.

Kulke, M.H., Freed, E., Chiang, D.Y., Philips, J., Zahrieh, D., Glickman, J.N., Shivdasani, R.A., 2008. High-resolution analysis of genetic alterations in small bowel carcinoid tumors reveals areas of recurrent amplification and loss. Genes Chromosom. Cancer 47, 591-603. https://doi.org/10.1002/gcc.20561.

Lage-Castellanos, A., Martínez-Montes, E., Hernández-Cabrera, J.A., Galán, L., 2010 False discovery rate and permutation test: an evaluation in ERP data analysis. Stat. Med. 29, 63-74. https://doi.org/10.1002/sim.3784.

Laurie, C.C., Doheny, K.F., Mirel, D.B., Pugh, E.W., Bierut, L.J., Bhangale, T., Boehm, F., Caporaso, N.E., Cornelis, M.C., Edenberg, H.J., Gabriel, S.B., Harris, E.L., Hu, F.B., Jacobs, K.B., Kraft, P., Landi, M.T., Lumley, T., Manolio, T.A., McHugh, C., Painter, I., Paschall, J., Rice, J.P., Rice, K.M., Zheng, X., Weir, B.S., 2010. Quality control and quality assurance in genotypic data for genome-wide association studies. Genet. Epidemiol. 34, 591-602. https://doi.org/10.1002/gepi.20516.

Leishangthem, G.D., Mabalirajan, U., Singh, V.P., Agrawal, A., Ghosh, B., Dinda, A.K., 2013. Ultrastructural changes of airway in murine models of allergy and diet-induced metabolic syndrome. ISRN Allergy 2013, 261297. https://doi.org/10.1155/2013/ 261297.

Li, M., Shang, Y.X., 2014. Ultrastructural changes in rat airway epithelium in asthmatic airway remodeling. Pathol. Res. Pract. 210, 1038-1042. https://doi.org/10.1016/j. prp.2014.03.010.

Mabalirajan, U., Ghosh, B., 2013. Mitochondrial dysfunction in metabolic syndrome and asthma. J. Allergy 2013, 1-12. https://doi.org/10.1155/2013/340476.

Moraes, C.T., DiMauro, S., Zeviani, M., Lombes, A., Shanske, S., Miranda, A.F., Nakase, H., Bonilla, E., Werneck, L.C., Servidei, S., Nonaka, I., Koga, Y., Spiro, A.J.W., Brownell, A.K., Schmidt, B., Schotland, D.L., Zupanc, M., DeVivo, D.C., Schon, E.A., Rowland, L.P., 1989. Mitochondrial DNA deletions in progressive external 
ophthalmoplegia and kearns-sayre syndrome. N. Engl. J. Med. 320, 1293-1299. https://doi.org/10.1056/NEJM198905183202001.

Nakashima, T., Sekiguchi, T., Kuraoka, A., Fukushima, K., Shibata, Y., Komiyama, S. Nishimoto, T., 1993. Molecular cloning of a human cDNA encoding a novel protein, DAD1, whose defect causes apoptotic cell death in hamster BHK21 cells. Mol. Cell. Biol. 13, 6367-6374. https://doi.org/10.1128/MCB.13.10.6367.

Nishii, K., Tsuzuki, T., Kumai, M., Takeda, N., Koga, H., Aizawa, S., Nishimoto, T., Shibata, Y., 1999. Abnormalities of developmental cell death in Dad1-deficient mice. Genes Cells 4, 243-252. https://doi.org/10.1046/j.1365-2443.1999.00256.x.

Orlando, C., Pinzani, P., Pazzagli, M., 1998. Developments in quantitative PCR. Clin. Chem. Lab. Med. https://doi.org/10.1515/CCLM.1998.045.

Purcell, S., Neale, B., Todd-Brown, K., Thomas, L., Ferreira, M.A.R., Bender, D., Maller, J., Sklar, P., de Bakker, P.I.W., Daly, M.J., Sham, P.C., 2007. PLINK: a Tool Set for Whole-Genome Association and population-based linkage analyses. Am. J. Hum. Genet. 81, 559-575. https://doi.org/10.1086/519795.

Queiroz, G.A., Costa, R.S., Alcantara-Neves, N.M., Nunes de Oliveira Costa, G., Barreto, M.L., Carneiro, V.L., Figueiredo, C.A., 2017. IL33 and IL1RL1 variants are associated with asthma and atopy in a Brazilian population. Int. J. Immunogenet. 44, 51-61. https://doi.org/10.1111/iji.12306.

Redington, A.E., Howarth, P.H., 1997. Airway wall remodelling in asthma. Thorax 52, 310-312. https://doi.org/10.1136/thx.52.4.310.

Riordan-Eva, P., Harding, A.E., 1995. Leber's hereditary optic neuropathy: the clinical relevance of different mitochondrial DNA mutations. J. Med. Genet. 32, 81-87. https://doi.org/10.1136/jmg.32.2.81.

Rios, R., Silva, H.B.F.D., Carneiro, N.V.Q., Pires, A.O., Carneiro, T.C.B., Costa, R.D.S., Marques, C.R., Machado, M.S.S., Velozo, E.D.S., Silva, T.M.G.D., Silva, T.M.S.D., Conceição, A.S., Alcântara-Neves, N.M., Figueiredo, C.A., 2017. Solanum paniculatum L. decreases levels of inflammatory cytokines by reducing NFKB, TBET and GATA3 gene expression in vitro. J. Ethnopharmacol. 209, 32-40. https://doi.org/10. 1016/j.jep.2017.07.014.

Rodrigues, L.C., Newcombe, P.J., Cunha, S.S., Alcantara-Neves, N.M., Genser, B., Cruz, A.A., Simoes, S.M., Fiaccone, R., Amorim, L., Cooper, P.J., Barreto, M.L., 2008. Early infection with Trichuris trichiura and allergen skin test reactivity in later childhood. Clin. Exp. Allergy 38, 1769-1777. https://doi.org/10.1111/j.1365-2222.2008. 03027.x.

Silberstein, S., Collins, P.G., Kelleher, D.J., Gilmore, R., 1995. The essential OST2 gene encodes the 16-kD subunit of the yeast oligosaccharyltransferase, a highly conserved protein expressed in diverse eukaryotic organisms. J. Cell Biol. 131, 371-383. https://doi.org/10.1083/jcb.131.2.371.

Sole, X., Guino, E., Valls, J., Iniesta, R., Moreno, V., 2006. SNPStats: a web tool for the analysis of association studies. Bioinformatics 22, 1928-1929. https://doi.org/10. 1093/bioinformatics/btl268.

Strachan, D., Pearce, N., 2011. The Global Asthma Report 2011. Int. Union Against Tuberc. Lung Dis., pp. 18-19.

Suzuki, T., Nagao, A., Suzuki, T., 2011. Human mitochondrial tRNAs: biogenesis, function, structural aspects, and diseases. Annu. Rev. Genet. 45, 299-329. https://doi. org/10.1146/annurev-genet-110410-132531.

Tanaka, K., Kondoh, N., Shuda, M., Matsubara, O., Imazeki, N., Ryo, A., Wakatsuki, T., Hada, A., Goseki, N., Igari, T., Hatsuse, K., Aihara, T., Horiuchi, S., Yamamoto, N., Yamamoto, M., 2001. Enhanced expression of mRNAs of antisecretory factor-1, gp96, DAD1 and CDC34 in human hepatocellular carcinomas. Biochim. Biophys. Acta - Mol. Basis Dis. 1536, 1-12. https://doi.org/10.1016/S0925-4439(01)00026-6.

Teixeira, H.M.P., Alcantara-Neves, N.M., Barreto, M., Figueiredo, C.A., Costa, R.S., 2017. Adenylyl cyclase type 9 gene polymorphisms are associated with asthma and allergy in Brazilian children. Mol. Immunol. 82, 137-145. https://doi.org/10.1016/j. molimm.2017.01.001.

Ter-Minassian, M., Wang, Z., Asomaning, K., Wu, M.C., Liu, C.Y., Paulus, J.K., Liu, G. Bradbury, P.A., Zhai, R., Su, L., Frauenhoffer, C.S., Hooshmand, S.M., de Vivo, I., Lin, X., Christiani, D.C., Kulke, M.H., 2011. Genetic associations with sporadic neuroendocrine tumor risk. Carcinogenesis 32, 1216-1222. https://doi.org/10.1093/ carcin/bgr095.

Vandesompele, J., De Preter, K., Pattyn, ilip, Poppe, B., Van Roy, N., De Paepe, A., Speleman, rank, 2002. Accurate normalization of real-time quantitative RT-PCR data by geometric averaging of multiple internal control genes. Genome Biol. 3https://doi. org/10.1186/gb-2002-3-7-research0034. 34-1.

Wallace, D.C., Chalkia, D., 2013. Mitochondrial DNA genetics and the heteroplasmy conundrum in evolution and disease. Cold Spring Harb. Perspect. Biol. https://doi. org/10.1101/cshperspect.a021220.

Wang, K., Gan, L., Kuo, C.L., Hood, L., 1997. A highly conserved apoptotic suppressor gene is located near the chicken T-cell receptor alpha chain constant region. Immunogenetics 46, 376-382.

Wang, S.B., Weng, W.C., Lee, N.C., Hwu, W.L., Fan, P.C., Lee, W.T., 2008. Mutation of mitochondrial DNA G13513A presenting with Leigh syndrome, wolff-parkinsonwhite syndrome and cardiomyopathy. Pediatr. Neonatol. 49, 145-149. https://doi. org /10.1016/S1875-9572(08)60030-3.

Wight, T.N., Frevert, C.W., Debley, J.S., Reeves, S.R., Parks, W.C., Ziegler, S.F., 2017. Interplay of extracellular matrix and leukocytes in lung inflammation. Cell. Immunol. https://doi.org/10.1016/j.cellimm.2016.12.003.

Yang, J., Benyamin, B., McEvoy, B.P., Gordon, S., Henders, A.K., Nyholt, D.R., Madden, P.A., Heath, A.C., Martin, N.G., Montgomery, G.W., Goddard, M.E., Visscher, P.M., 2010. Common SNPs explain a large proportion of heritability for human height. Nat. Genet. 42, 565-569. https://doi.org/10.1038/ng.608.Common. 